\title{
PASADO RECIENTEY PUBLICACIONES PERIÓDICAS. UNA APROXIMACIÓN PARA LEER LAS POLÉMICAS SOBRE EL GENOCIDIO ARGENTINO (1983-2001)
}

\section{Recent past and periodicals. An approach to reading the controversies about the argentine genocide (1983-2001)}

\author{
Bruno Ragazzi* \\ Universidad Nacional del Nordeste \\ bruno.ragazzi@comunidad.unne.edu.ar
}

Palabras clave

publicaciones periódicas;

posdictadura;

memoria

\section{Resumen}

En el presente trabajo se aborda la relación entre pasado reciente y publicaciones periódicas. Se parte de la hipótesis de que los intelectuales en revistas y diarios toman posición en relación con el pasado a partir de la jerarquización de libros y estéticas que, al mismo tiempo, se traducen en elecciones políticas e ideológicas. En este sentido se abordarán las lecturas sobre el pasado reciente elaboradas por los intelectuales que tuvieron una posición dominante dentro del campo intelectual como Beatriz Sarlo, Héctor Schmucler, María Teresa Gramuglio, con el fin de intentar reconstruir los itinerarios de las polémicas sobre el pasado reciente, durante la posdictadura. Se piensa que, si bien durante la transición democrática se realizaban lecturas atravesadas por políticas residuales de los sesenta, con las diversas coyunturas del periodo posdictatorial irán cediendo hacia otros posicionamientos.

\begin{abstract}
The present work addresses the relationship between the recent past and regular publications. The hypothesis is that the intellectuals in periodicals take a stand concerning to the past through the hierarchization of books and aesthetics that, at the same time, can be translated into political and ideological choices. In this sense, the interpretation the recent past done by intellectuals who had a dominant position within the intellectual field such as Beatriz Sarlo, Héctor Schmucler, María Teresa Gramuglio, will be addressed in order to try to reconstruct the itineraries of the controversies about the recent past, during the post-dictatorship. It is thought that, although during the democratic transition interpretations of the residual policies of the sixties were carried out, with the various scenarios of the postdictatorial period, they would gradually give way to other positions.
\end{abstract}

Keywords 


\title{
Pasado reciente y publicaciones periódicas. Una aproximación para leer las polémicas sobre el genocidio argentino (1983-2001)
}

\author{
Mnemosine (...) no es la que va hacia el pasado \\ Es la que tiene en el presente la memoria, el origen. \\ Mnemosine es la que cuenta. \\ Nicolás Casullo ${ }^{1}$
}

El epígrafe de Nicolás Casullo que abre este texto permite pensar una relación de temporalidades, la de un pasado remoto o reciente que es visto a través de los ojos de la contemporaneidad. Esa relación se da lugar a través de dispositivos diversos, que objetivizan la memoria de un grupo o una clase, y que tienen diversos niveles de circulación en la sociedad, como el de las publicaciones periódicas.

En el siguiente artículo se abordará la vinculación entre pasado reciente y publicaciones periódicas. Se centrará en ver cómo a través de las revistas algunos de los críticos que tuvieron un lugar dominante en el campo intelectual como Beatriz Sarlo, María Teresa Gramuglio, Héctor Schmucler, tomaron posición respecto del genocidio y la violencia de Estado, a través de la literatura que jerarquizan y promocionan sobre este asunto durante el período posdictatorial. Algunas de las preguntas que surgen de esta relación son: ¿cuáles son las novelas y testimonios que versan sobre el pasado reciente que se promocionan en revistas? ¿cuáles son las estéticas y géneros que se privilegian en torno a la narrativa acerca del pasado reciente? ¿cuáles son los posicionamientos ideológicos que se puedan inferir a partir del análisis de la jerarquización, selección y crítica de textos sobre el pasado reciente?

En esta oportunidad se examinan las tomas de posición respecto al pasado reciente en el periodo posdictatorial, 1983-2001, que abarca desde la transición democrática hasta la eclosión social del 2001, atravesado por el régimen de memoria de "los dos demonios" (Crenzel, 2008; Feierstein, 2018). Se cree que los intelectuales toman distintas posiciones a lo largo del recorte, atravesados por coyunturas diversas marcadas por acontecimientos como la publicación del Nunca más y el Juicio a las juntas, el dictado de las leyes de Obediencia debida y Punto final, la edición del best seller testimonial La voluntad de Eduardo Anguita y Martín Caparrós. ${ }^{2}$

1. Casullo, 2004, p. 31.

2. Este texto parte de una investigación que examina tres suplementos culturales de gran capital simbólico y económico, como Radar. La otra mirada, N. Revista de cultura y $A D N$ en el período 2003-2015 para pensar en las tomas de la palabra en el espacio público respecto de la dictadura militar y los años de plomo, vistos a través de la jerarquización de novelas y testimonios. Sin embargo, se cree que toda toma de posición en un corte determinado está relacionada con un espesor histórico. Así, en la medida en que un gesto se actualiza o en que lo muerto encarna en lo vivo (Bourdieu, 1980), referir a las dinámicas dentro del campo intelectual de un tiempo determinado es también referir a su pasado. 
El relevamiento de las tomas de posición de todas las publicaciones circulantes en el campo intelectual posdictatorial excedería el límite de estas páginas, por su complejidad. Siguiendo la lógica bourdesiana que supone que hay agentes que poseen más capital que otros, que establecen sentidos o huellas en la memoria del campo, se ha creído conveniente leer aquellas firmas que tuvieron una posición dominante en el ámbito intelectual. Hemos optado por aquellos que provienen de la izquierda intelectual (Bourdieu, 1995). ${ }^{3}$

En cuanto la organización del texto, en primer lugar, se establecerán algunas conceptualizaciones teóricas para pensar la relación publicaciones periódicas y pasado reciente. Luego, en segundo lugar, se abordarán las posiciones en torno al pasado reciente en el campo intelectual, en el periodo posdictatorial.

\section{Las polémicas sobre el pasado reciente y las publicaciones periódicas}

$\mathrm{El}$ abordaje de la relación entre pasado reciente y publicaciones periódicas permite pensar en cómo se construyó el genocidio argentino (Feierstein, 2007, 2018) como tomas de posición y objeto de disputas, de polémicas, que se dieron lugar a partir de la transición democrática. Esto es, discusiones que atravesaron y atraviesan subrepticiamente la cultura (Panesi, 2018). Específicamente, las polémicas que aquí se abordan se reflejan en la jerarquización de estéticas y nombres que son, de alguna manera, elecciones políticas, legibles a partir de la promoción y mención de libros.

El análisis de las "polémicas" sobre el pasado reciente se puede realizar a partir de cortes temporales precisos. Un primer período que abarque la posdictadura (1983-2001), es decir, desde la transición, en su complejidad de discursos residuales y emergentes, y el establecimiento del "régimen de memoria” (Crenzel, 2014) de los “dos demonios”, hasta su clausura, con la implosión políticosocial del 2001. Este último hecho supone la apertura de una nueva etapa en la historia cultural argentina (Schwarzböck, 2015; Gerbaudo, 2016). Asimismo, la disolución del régimen de memoria bidemónico del Nunca más (Feierstein, 2018). La continuidad de este segundo período (2003presente) se caracterizó por una serie de políticas públicas, como la reapertura de los juicios a genocidas, establecimiento de numerosos lieux de mémoire, que generaron la jerarquización del tema del genocidio y la violencia política, que se traspusieron en escrituras y encendidos debates.

\footnotetext{
3. Si bien en este trabajo se ha optado por trabajar con las firmas mencionadas, es necesario trazar un mapa intelectual del amplio movimiento de la izquierda en el periodo posdictatorial. Roxana Patiño (2003) a partir de los conceptos de Raymond Williams de "proyecto intelectual" y "formación" elabora una cartografía del posicionamiento de los diversos agentes de la izquierda y de la franja progresista del peronismo alrededor de las revistas en la posdictadura, cada uno con su proyecto político-intelectual. Este mapa se encuentra compuesto por diversas "zonas intelectuales": la de izquierda posmarxista, alrededor de las publicaciones Punto de vista (1978-2003), La ciudad futura (1986-2004); la de la izquierda marxista, con El cielo por asalto (1990-1994), y El rodaballo (1994-2006); la del peronismo de izquierda no marxista, alrededor de El ojo mocho (1994-2008). Además, una zona marxista-leninista, alrededor de Causas y azares (1994-1998); y, finalmente, una zona alejada de lo "estrictamente político", pero con intersecciones y diálogos con discusiones en cauce con esas preocupaciones, se encuentran Confines (1995-1997) y Pensamiento de los confines (1997-continúa). Es de notar en este recorrido que traza Patiño, que muchas publicaciones llegan a término a partir de la asunción del gobierno del peronismo progresista de Néstor Kirchner, evidencia que acompaña la hipótesis de Silvia Schwarzböck (2015) acerca de la organicidad de muchos de estos intelectuales, y el abandono de las publicaciones de carácter contra-dominantes.
} 
En vinculación con la elección del objeto publicaciones periódicas para leer las tomas de posición respecto al pasado reciente, se conciben las revistas y los suplementos culturales como "catalizadores" de las polémicas. Esto es, se los piensa como difusores de ideologías y estéticas en las que participan principalmente intelectuales que buscan tener alguna injerencia en el espacio público (Rivera, 1995; Sarlo, 1992). Asimismo, se entiende por "pasado reciente" un período que forma parte de la historia actual, y que permanece en la memoria de la sociedad como un período "caliente", particularmente por su carácter violento y traumático. Si bien el período es difícilmente historizable, existe cierto consenso general en establecer su inicio con el Cordobazo en 1969 y su clausura, con el Juicio a las Juntas y la publicación del Nunca más en el bienio 1984-1985 (Franco y Levin, 2007).

Por último, esta manera de leer los diversos posicionamientos sobre los años de plomo y el genocidio sigue a Carlos Pescader (2017), quien sostiene que analizar el período postdictatorial y sus continuidades es una manera de combatir contra las múltiples políticas del olvido que se fueron estableciendo desde 1983. No solo se refiere a los indultos y las amnistías dictadas a fines de los 80, también a múltiples intervenciones en el espacio público que sostienen discursividades de memorias cristalizadas, y negacionistas.

\section{El periodo posdictatorial: del clasismo estético al mercado (1983-2001)}

El período posdictatorial se inicia en un periodo confuso entre el fin de la guerra de Malvinas, en 1982, la asunción del presidente Raúl Alfosnín, en diciembre de 1983, luego de la elección presidencial en la que ganó a Ítalo Luder por el 51\% de los votos, la ejecución del juicio a las Juntas y la publicación del libro de testimonios Nunca más, en el bi-año 1984-1985 (Franco y Levin, 2007). Finaliza, como se adelantó, con una serie de cambios culturales y políticos, que alcanzaron su eclosión en la crisis de 2001.

Se cree que este corte puede subdividirse en tres. Se tienen en cuenta hechos específicos que permiten trazar un itinerario de los intelectuales en relación con cómo plantean sus posicionamientos en el campo respecto de estéticas y las formas de contar el genocidio, muchas veces cuestionando el régimen de memoria dominante del Nunca más (Crenzel, 2008). Se sigue la idea de que estos posicionamientos se relacionan con procesos obturados por el golpe de Estado, y que se retoman en la transición, como el internacionalismo. Si bien estos se intentan mantener a lo largo del período, van adquiriendo matices que permiten pensar en divisiones. Estos subcortes se encuentran marcados por la publicación del Nunca más y el juicio a las Juntas, las posteriores amnistías de fines de los ochenta, y la explosión mediático-editorial de 1995, catalizado por las declaraciones del jefe de corbeta Adolfo Scilingo, la publicación del best seller La voluntad de Eduardo Anguita y Martín Caparrós, el estreno de Cazadores de utopias de Isidro Blaustein. Se tomarán índices de muestras mayores que marcan este recorrido de discusión intelectual.

4. Los catalizadores son aceleradores de reacciones químicas o eléctricas. Se opta por la metáfora proveniente de otros campos disciplinares siguiendo el vocablo y la posición epistemológica bourdesiana, que será presentada más adelante. 
En relación con el primer corte, el período posdictatorial en sus inicios se caracterizó por el fervor y la reactivación de debates que habían sido obturados por el gobierno militar, sobre todo en el ala política intelectual de la izquierda. Estas discusiones se relacionaban con repensar su posición política, su ejercicio desde el campo intelectual, y reflexionar acerca de cómo asir los hechos traumáticos vividos durante los años de plomo. En este contexto, la publicación del Nunca más, en sus versiones televisiva y en libro, supondría un hecho cultural para discutir estéticamente cómo pensar los años dictatoriales.

En primer lugar, el Nunca más sugiere una posición ideológica de carácter residual que tenía una amplia presencia en el complejo social de la época. Explicitada en la emisión televisiva por el ministro del interior Antonio Trócoli, la "teoría de los dos demonios" suponía un enfrentamiento armado, de iguales proporciones, entre facciones que habían detonado la violencia armada, y exceptuaba a la sociedad de toda responsabilidad. ${ }^{5}$

Asimismo, el Informe Nunca más estableció una lectura inaugural acerca de las desapariciones, y de las responsabilidades sobre las Fuerzas Armadas. Elaboró un relato construido a partir de los crímenes realizados por estas, con un lenguaje fundado en el ámbito de lo jurídico que inauguró el "paradigma punitivo". Asentó una verdad que invitó a hacer justicia, y se transformó en canon interpretativo del pasado del cual se irían elaborando discusiones en torno a ese tiempo, en el porvenir (Crenzel, 2014, p. 129). En este sentido, Rossana Nofal (2010) denominó al conjunto de testimonios del Nunca más, releyendo un concepto de Frederick Jameson, "relato maestro". Es decir, un relato que sirve para sucesivas interpretaciones, que permite reflexionar acerca de cómo "artefactos históricos se reescriben en términos de un relato profundo subyacente y más 'fundamental' de un relato maestro oculto que es la clave alegórica o el contenido figurativo de una primera secuencia de materiales empíricos" (2010, p. 52).

La revista Punto de vista ${ }^{6}$ que había circulado clandestinamente durante el período dictatorial, tomó la palabra en torno al debate sobre el pasado reciente, la asunción democrática, y la circulación de estos textos muy tempranamente, y que los suplementos periódicos como Cultura y nación del diario Clarín ${ }^{7}$ amplificarían en un escenario menos restringido, pero sin su potencia crítica.

\footnotetext{
5. Sostiene Hugo Vezzetti que si se quiere rastrear los orígenes de la "teoría de los dos demonios" se deben tomar en cuenta "las condiciones que resultaban de esa arraigada fe militarista en la que coincidían guerrilleros y represores. En la medida en que las acciones las declaraciones de la insurgencia armada se aislaban cada vez más de su propia base social y perdían toda posibilidad de ser recibidas por una sociedad harta del caos y la violencia, se favorecía la imagen de un conflicto que se dirimía entre aparatos aislados, por encima y al margen de lo que estaba al alcance de la gente común" (2002, p. 124-125). Un análisis pormenorizado del origen y desarrollo de esta "teoría" se encuentra en Franco y Levin (2007).

6. La revista Punto de vista (1978-2003) fue una revista heredera de la renovación crítica establecida por Los libros. En ella participaron intelectuales de gran representatividad en el campo crítico como Beatriz Sarlo, Carlos Altamirano, Ricardo Piglia, Hugo Vezzetti, o Miguel Sazbón. Puso en circulación lecturas de Raymond Williams y Pierre Bourdieu, fundó una nueva forma de leer la literatura argentina, y un canon interpretativo de larga duración. Estudios detallados sobre la revista son elaborados por Vulcano, 2000; Wortman, 2002; Dalmaroni, 2004; Patiño, 2006; Saítta, 2009.

7. El suplemento "Cultura y Nación" acompañó al diario Clarín desde su creación en 1945. En 2003 se establecería una renovación de la edición, como publicación autónoma que saldría semanalmente los sábados y nuevo diseño, con N. Revista de cultura.
} 
En un conocido texto, "Una alucinación en dispersa agonía", en el número del 21 de agosto de 1984 de Punto de vista, Beatriz Sarlo debate acerca de cuáles serían las claves para hablar sobre el pasado y, al tiempo, del presente. Propone recuperar el pasado y la memoria a partir de diversas subjetividades que se debe realizar más allá de las simetrías, y no a partir de las tranquilizadoras equivalencias "entre pueblo autoritario y gobierno autoritario" (1984, p. 1).

En ese texto, Sarlo sostiene que elaborar el pasado, hablar de la muerte, y pensar puentes entre el pretérito y el presente se pueden realizar de múltiples maneras. Para enfrentar estas inquietudes la crítica intenta explorar una serie de documentos culturales que montan un acercamiento al pasado reciente desde múltiples perspectivas.

Así, se mencionan las emisiones de los telediarios, el sensacionalista "show del horror" de la transición que Sarlo no duda en calificar de "grand-guignol". Lo descarta rápidamente de la discusión. El texto se centra en el informe Nunca más que transmitió "esa misma televisión” (1984, p. 2). En vinculación con el Informe, se lo lee como un conjunto de relatos "iluminados por el tono mate de la muerte secreta" (ibid.). El conjunto de las voces que ha sido víctima de la violencia estatal "propone un ejercicio colectivo a la sociedad argentina: transformar una pesadilla que solo unos pocos querían o debían recordar al despertarse, en un pasado común" (ibid.). Sarlo sostiene, a lo largo del texto, que el conjunto de testimonios se encuentra construido desde un "tono medio", a partir del cual el horror es rodeado sin énfasis y con cierto pudor. Concluye que pensar en esta estética del "tono medio" le permite leer esa producción cultural desde lo que Roland Barthes llamaba "opción moral". ${ }^{8}$

En contraste con el Nunca más, Sarlo lee un texto para intentar abordar la crispación desde la cual puede ser construido el pasado. El texto de Pablo Giussani, Montoneros, la soberbia armada, reconstruye desde una mirada crítica la representación de mencioanda agrupación, en torno de la muerte y la tortura, desde un lenguaje que define "exasperadamente la exasperación, exageradamente al exceso" (Sarlo, 1984, p. 3). La estetización de la muerte, mediante la cual, "los montoneros citaban a la muerte para ponerla en escena" (ibid.), le permite ponerlas en constelación con una serie de lecturas del sacrificio construido desde la belleza, del "heroísmo teologizado", casi absurdo, con las cartas a Vicky de Rodolfo Walsh, y la despedida que le hiciese Juan Gelman a Paco Urondo.

Asimismo, se abordan textos para tratar el tema del exilio. "Exilios" de Juan Gelman y Osvaldo Bayer. Sarlo los lee demasiado sentimentales y nostálgicos. Sostiene que Gelman escribe "poemas previsibles sobre las generosidades de la muerte que era, en realidad, la vida. ¿Qué es esto? ¿Es posible que la nostalgia clausure los lugares de la razón?” (1984, p. 4).

8. Para Roland Barthes en El grado cero de la escritura (1973), el estilo, o la estética, supone un objeto que es vehiculizado a través de la escritura, cuyo destinatario es la sociedad. La escritura, de esta manera, se concibe como mediación entre creación y sociedad. La reflexión sobre la escritura, el estilo, supone pensar en el uso social de la misma, de manera que "la escritura es esencialmente la moral de la forma, la elección del área social donde el escritor decide situar la Naturaleza de su lenguaje" (p. 23). También en la Lección inaugural, Barthes habla acerca de un lenguaje atravesado por diversas instituciones, ante la imposibilidad de la salida de una lengua sumida, propone "dirigido contra la generalidad, contra la gregariedad, contra la moralidad del lenguaje (...) hacer trampas con la lengua, hacerle trampas a la lengua” (1993, p. 121). En esta línea de pensamiento, Sarlo parece referir a la opción moral, como aquel lenguaje neutro, universal, y sostenido dentro de una tradición histórica, en contraposición de un estilo "desgarrador". 
Por último, La casa y el viento de Héctor Tizón constituye un "viaje hacia lo inarticulado", que tiene como centro la memoria y el exilio, sin hablar del exilio. De esta forma, considera positivamente que la literatura pueda tratar de pensar temas que, por su condición siniestra, inefable, se resisten a ser tratados o sean tratados oblicuamente, y que, al tiempo, son bellos y conmovedores. Esta preferencia por textos alegóricos será una constante en Sarlo, que preferirá leer junto a Tizón a Juan José Saer, David Viñas, y Ricardo Piglia, en detrimento de testimonios y textos realistas que fundan los protocolos del decir sobre la violencia estatal de los setenta.

Se cree que esta lectura, que jerarquiza esta práctica en favor de estéticas altamente formales u oblicuas, posee una relación residual con la ideología de la "pasión por lo real" y con el internacionalismo. En cuanto a lo primero, Alain Badiou (2005) dice que las representaciones son materializaciones de la ideología y que, particularmente el siglo XX, suponen un corte que desconfía de lo real, que quiere re-presentar lo real. Estas representaciones pueden pensarse de dos maneras, por la sustracción y por la destrucción. La sustracción borra toda huella del contenido de arte (Cuadro blanco sobre blanco de Malevich es el ejemplo más claro) y establece una distancia con lo real. La destrucción se encuentra atravesada por una "pasión por lo real" que constituye una operación "identitaria”. Al ser pensada como auténtica implica una depuración, que se traduce en diversas relaciones con lo real: "captar la identidad real, desenmascarar copias, desacreditar los falsos semblantes” (2005, p. 79).

En segundo lugar, se había comentado anteriormente que retomar procesos obturados por el golpe de Estado habían formado parte de la agenda intelectual. Los posicionamientos insistentes por parte de la izquierda intelectual por las estéticas oblicuas o "altamente formales", que recuperaron el debate entre realismo y vanguardia, o entre vanguardia política y vanguardia artística que se inició a mediados de los sesenta (Giunta, 2008), supusieron establecer un horizonte hacia autonomía del campo, perdida por la violencia política y la erosión de las posiciones de los intelectuales durante la dictadura. Por último, se cree que la recuperación de la autonomía supone también, eventualmente, la posibilidad de generar espacios de intervención política. ${ }^{9}$

En cuanto al segundo corte, se vincula con el dictado de las leyes de Punto final (1986) y Obediencia debida (1987). Estas legislaciones, por un lado, establecieron una fecha de caducidad a los juicios por crímenes perpetrados durante el terrorismo de Estado; y, por otro, la eximición de la responsabilidad en estos por estar vinculados con la cadena de mando. Estas rompieron la "formación simbólica" que se había solidificado con el advenimiento democrático. Por "formación simbólica” se

\footnotetext{
9. De esta manera lo imagina Pierre Bourdieu a partir de la intervención de Émile Zola en el caso Dreyfus. Sostiene que "[el] intelectual se constituye como tal al intervenir en el campo de político en el nombre de la autonomía y de los valores específicos de un campo de producción cultural que ha alcanzado un elevado nivel de dependencia con respecto a los poderes, y no como el hombre político que dispone de un importante capital cultural (...) [que] encerrado en su mundo, adosado a sus propios valores de libertad, de desapego de justicia, que excluyen que pueda abdicar de su autoridad, y de su responsabilidad específicas a cambio de unos beneficios o de unos poderes temporales necesariamente devaluados, se afirma, en contra de las leyes específicas de la política, de las de la Realpolitik y de la razón del Estado” (1995, p. 197-198. Cursivas en el original).
} 
refiere al rechazo hacia la violencia política, y la veracidad sobre las desapariciones y su corpus probatorio (Crenzel, 2014, p. 147).

Asimismo, una serie de transformaciones vinculadas con el aterrizaje definitivo del paisaje neoliberal y los medios de comunicación fueron ganando cada vez más espacio en la esfera pública. En este contexto, la palabra política y las promesas vinculadas con el castigo de los culpables por los crímenes cometidos durante la dictadura, que rodearon el pasaje democrático, fueron licuados por los medios de comunicación y el olvido. El conflicto político, la crisis hiperinflacionaria de fines de los 80, los gestos de amnistía que se fueron instalando paulatinamente en la escena pública no podían asirse en la velocidad que ofrecía la televisión.

Los intelectuales debían combatir contra un doble frente en íntima relación, que se vinculaba con el "llamado a la reconciliación" y las invitaciones al olvido: los gestos de amnistía e impunidad y la gestión sobre los medios de comunicación. Si bien estos últimos habían perdido legitimidad durante el "show el horror" y sospechas de silenciamiento y complicidad con los horrores de la dictadura, tenían ahora una presencia inédita de tal manera que no hay, efectivamente, una "lógica de la Academia, otra de la Cultura y otra de los Medios" (Schwarzböck, 2015, p. 81).

Ante esto, la posición de los intelectuales que es legible en textos como "Una alucinación en dispersa agonía" toma otro cariz. En un texto de Beatriz Sarlo de 1987, publicado en el n³0 de Punto de vista, "Los militares y la historia: contra los perros del olvido", puede leerse efectivamente a la par del texto de 1984 para establecer contrastes en dos momentos de la transición democrática.

Efectivamente, "Los militares y la historia: contra los perros del olvido" abre con dos poemas que recuerdan no ceder al silencio y mantener el compromiso ante el olvido. Uno de Juan Gelman ("muertos que hablo y que me hablan / en las palabras que apalabro"); y otro, de Antonio Marimón ("Dos enterradores trabajaban de sol a sol /(...)/ y su condena era reiniciar diariamente / la tarea"). Entre estos dos gestos, el de la persistencia a la conversación con la muerte o con la presencia del detenido-desaparecido, y la del entierro, es que le permite a Sarlo leer un arco estético que abarca de las escrituras más "formales" al realismo. La oscilación entre recuerdo y olvido sirven para pensar el pasado "a partir de un repertorio acierto de cualidades: kafkiano, borgeano arltiano, balzaciano (...) [que] iluminan exactamente la configuración de un hecho, la dimensión de una experiencia, la forma de un sentimiento, la conciencia de un límite" (1987, p. 6). Es decir, aquel orden que disfraza o alegoriza, y aquel otro que muestra o referencia.

Este arco, en cuyos extremos se encuentran lo oculto y lo mostrado, se concibe, no con cómo imaginar la escritura en torno al pasado reciente desde una posición "autotélica" como en "Una alucinación...”, sino el para qué, su función. Cuando habla de los textos relacionados con la dictadura sostiene Sarlo:

No me refiero solamente a los discursos altamente referenciales como el informe de la CONADEP y las actas de los juicios. Hay novelas, poemas, testimonios, en un arco que va de la 
extrema representación realista hasta las transformaciones más distanciadas. Son obstáculos puestos ante la invitación, la posibilidad o la imposición del olvido. (1987, p. 7)

Luego de su asunción, Carlos Menem, ante la salida intempestiva de Raúl Alfonsín, realizó un acercamiento hacia la derecha y firmó las amnistías de numerosos agentes militares que profundizó las gramáticas del olvido, inauguradas en la gestión anterior. Ante esto, los intelectuales perdieron alguna esperanza de intervención política en el espacio público.

En relación con esto, interesa particularmente un dossier publicado en Babel ${ }^{10}$ en junio de 1989 titulado, "Lecturas del peronismo, la revisión de las masas", coordinado por Horacio González, y constituido por artículos de Christian Ferrer, Eduardo Rinesi y Federico Galende, Beatriz Sarlo y Héctor Schmucler. El dossier tiene como fin trazar un mapa del fenómeno peronista a través de lecturas diversas con el fin de responder a qué es lo que ha pasado con el peronismo, o mejor, que ha pasado con el peronismo luego de la asunción de Menem.

El artículo de Sarlo, "Montoneros: delfines y soldados" (1989) centra su lectura en los textos cuyo fin es la reconstrucción de la lucha armada, el secuestro, el violento confinamiento obligado y la muerte, como son los de Miguel Bonasso, Recuerdo de la muerte, Juan Gasparini, Montoneros, final de cuentas, y Pablo Guissani, Montoneros, la soberbia armada. En este extraño corpus compuesto por obras de algún grado de ficcionalización y textos periodísticos o de investigación, si bien Sarlo retoma el imperativo de la lectura de estos textos como herramienta que persigue aquello que el recuerdo diluye y borra, corrige y observa matices de los relatos. Las observaciones se centran principalmente en la relación con los orígenes de Montoneros y su filiación con el peronismo. Al tiempo, tamiza su abordaje a partir de la lectura del fin de los grandes relatos. En efecto, respecto de Recuerdo de la muerte sostiene que exhibe la artificiosidad del non-fiction, y que, "es preciso leer los hechos transmitidos por Bonasso y Gasparini como si perteneciesen al orden recóndito de los sueños o al orden extranjero de otra cultura" (1989, p. 27). Parece ser que hace alusión a la clausura de otros tiempos, el de la modernidad y sus verdades, y por agregado, también a la obturación del recuerdo y su orden caduco.

Este gesto paradojal de Sarlo es significativo para pensar en la circulación de textos como el de Bonasso en el espacio intelectual. Al tiempo que muestra, realiza las obturaciones críticas de los inicios de la transición contra las formas realistas. Cabe destacar que la novela de Bonasso, es un testimonio ficcionalizado, y constituye un texto matriz del género testimonial en Argentina que permite pensar en el primer boceto de la transmisión de experiencias inéditas en Argentina (Nofal, 2001).

En íntima vinculación con las afirmaciones de Sarlo, el artículo de Héctor Schmucler, "La única verdad es el relato" (1989), dedicado a La novela de Perón de Tomás Eloy Martínez, abre con una serie

10. Babel. Revista de libros (1989-1991) fue una revista que constituyó una suerte de continuidad de la primera etapa de Los libros, en el proyecto de ofrecer, ante una notable crisis del mercado editorial a fines de los ochenta, un catálogo de lecturas. En ella participaron Martín Caparrós, Daniel Guebel, Alan Pauls, Luis Chiatarroni, Sergio Chejfec, Jorge Dorio y Sergio Bizzio de marcadas inclinaciones hacia el experimentalismo, el exotismo, el juego metaficcional y la teoría literaria, que los enfrentaría, de alguna manera, con los "planetarios" nucleados alrededor de la "Biblioteca del sur", de la editorial Planeta (Saítta, 2009). Cabe aclarar que esta revista no es identificable con el ala intelectual izquierda, pero interesa el tratamiento sobre el peronismo progresista que se detalla a continuación. 
de preguntas que ponen en cuestión el relato verdadero como unívoco vínculo para contar la verdad de los horrores del pasado:

¿Existe otra historia que no sea el relato de la historia? ¿Los hechos tienen significación antes de pertenecer a la trama que el relato constituye? ¿Cuáles son, si es que existen, los límites entre el relato friccional y el de la historia? Si el relato (de relacionar, vincular algo con algo) otorga sentido a las cosas, asume la intransferible responsabilidad de asumir una verdad. (1989, p. 28)

El relato de Eloy Martínez se construye a partir de diversos materiales que se utilizaron para armarlo: cartas, testimonios, entrevistas, memorias, grabaciones del dirigente. Contrariamente a la consigna de Perón, que reza que la única verdad es la realidad, la novela "devela que la única verdad es la ficción”. Concluye que "La Argentina es un país de relatos. Pero de relatos que preceden a la historia, que la hacen. Mitos fundadores, sin pasado para recordar, sin lugar de regreso, construye permanentemente su realidad" (Schmucler, 1989, p. 28).

Se presenta, de esta manera, una poética del recuerdo fundada sobre el vacío, en el que impera el descrédito, y se organiza a partir de múltiples relatos y materiales. En ese mismo dossier, dice Christian Ferrer acerca de la obra de Rodolfo Walsh, que sus relatos se encuentran construidos a partir de collages y calcos de realidad, y se pregunta “¿qué mejor que un pastiche literario para escribir sobre este país?” (1989, p. 27).

El tercer corte temporal se establece a partir del año 1995, luego de un largo silencio impuesto por las amnistías y la pérdida de espacio de los intelectuales en la escena pública. Una serie de hechos catalizaron llamados a posicionarse en la esfera pública en relación con el pasado reciente. Se dieron lugar las declaraciones de Adolfo Scilingo sobre los vuelos de la muerte; la publicación de La Voluntad. Una bistoria de la militancia en Argentina de Anguita Caparrós, que rápidamente se convirtió en récord de ventas, y que abría un nuevo capítulo en la narrativa sobre el pasado reciente. El estreno de Cazadores de utopias, y Montoneros. Una bistoria en el bi año 1994-1995, generó revuelo entre los intelectuales por su marcado tono nostálgico en relación con la militancia y el llamado a las armas. La emergencia de la agrupación H.I.J.O.S., en esa misma coyuntura, agregaría un nuevo sujeto social a la constelación de los familiares de desaparecidos, junto con la práctica del escrache (Sorénduguer, 2001; Dalmaroni, 2004).

Este boom memorialístico (Lvovich y Bisquert, 2008) llamó a los intelectuales a intervenir en la circulación masiva de productos sobre el pasado reciente con el fin salvaguardar el recuerdo del olvido. Muchas de las narrativas sobre el pasado habían sido elaboradas por los medios de comunicación y sostenían relatos cristalizados y heroizantes, que tenían más de amnesia que de recuerdo. En este sentido Hugo Vezzetti sostiene en dos oportunidades en "Variaciones sobre la memoria social", publicado en el n54 de Punto de vista, de 1996: "el trabajo de la rememoración requiere de quienes (políticos, pero, sobre todo intelectuales, escritores y artistas, instituciones y espacios colectivos de producción) sean capaces de sostener una compleja producción permanente" (1996, p. 3). Luego, de la misma manera, sostiene: "un mapa de la memoria social debería atender al 
papel de los 'intelectuales' en sentido amplio (docentes, periodistas, artistas y hombres de letras) en cuanto proporcionan discursos y relatos del pasado" (1996, p. 5).

En “Otra vez los fantasmas del pasado" (1997), en el n’58 de Punto de vista de agosto de 1997, Beceyro retoma la crítica a los productos de la industria cultural vinculados con el pasado reciente, y la construcción de los "mitos peronistas". Pone en constelación la película de Blaustein Cazadores de utopias con otros textos: El presidente que no fue. Los archivos secretos del peronismo, de Miguel Bonasso, un texto que explora a partir de documentos y memorias del propio Bonasso una explicación del fenómeno peronista y su actualización encarnada en la figura de Carlos Menem; Evita, la tumba sin paz, un recorrido biográfico de la vida de Eva Perón y el periplo y las luchas políticas de su cuerpo embalsamado; La voluntad. Una historia de la militancia revolucionaria en Argentina, de Eduardo Anguita y Martín Caparrós, una publicación de testimonios en 3 volúmenes que se convirtió rápidamente en un best-seller editorial. Asimismo, en el número 58 de Punto de vista, al que pertenece el artículo de Beceyro, obra de apertura un breve texto de Oscar Terán, "Pensar el pasado", en el que apela a los lectores a concebir el pretérito sin anacronismos, sin contextualismo relativista, y llama a la responsabilidad para narrar el pasado, ¿qué quiere decir narrar responsablemente? ¿por qué Beceyro abre su texto con "Todo comenzó con Cazadores de utopías de David Blaustein. Pero eso fue solo el comienzo" (1997, p. 20)? ¿de qué manera estos textos representan un problema para los intelectuales?

En "Cuando la política era joven" (1997), Beatriz Sarlo carga sobre La voluntad de Anguita y Caparrós y El presidente que no fue de Bonasso. Afirma que, en un escenario en el que la "prosa democrática" se yergue como una falta y es más pobre en ideas, y más mediocre en la medida en la que "el pathos republicano se diluye en la rutina de los derechos políticos", las historias épicas vanguardistas de la política se hacen necesarias. Sostiene que hay necesidad de historias no solo porque los engranajes de la democracia, que es rutinaria ya que debe acordar voluntades, y por momentos además es indecisa, sino porque la nostalgia del presente acucia a los más viejos y a los más jóvenes. En los primeros, argumenta, obra como una justificación el pasado subjetivo, de la violencia política que la restitución democrática no siempre obró como corte, "la excusa de que fuimos lo que debimos ser en cada momento parece más amable, aunque no sea la más exacta” (1997, p. 19); para los segundos, constituye una narración de un pasado lejano tamizado por la inmediatez del detalle y por la moda presente de las historias personales.

Al leer los textos de Bonasso y Anguita-Caparrós los lee bajo la luz del concepto de testimonio, como están clasificados ambos textos. Este, asegura Sarlo, se caracteriza, en este caso por la capacidad reconstructiva, por el detalle excesivo, que es en lo que funda su condición de verdad, aunque sea así, una verdad institucionalizada: "Como en un juicio, la verdad necesita del detalle. En este sentido la acumulación del detalle es parte del dispositivo de prueba. Y lo que se prueba no son los gustos literarios" (1997, p. 16). El problema no es solo el del libro y el de la memoria institucionalizada, sino también el de la larga extensión (600 páginas, tres volúmenes), que hace que el detalle se vuelva repetitivo, hasta el hartazgo. Y repite, asimismo, fórmulas y mitos de juvenilismo militar, pero en una prosa que es ya vieja y anquilosada. En ese sentido, afirma Sarlo, que si bien no está escrito para dar una nueva interpretación de los hechos El presidente que no fue 
es un libro fuertemente testimonial, pues no se trata de una memoria del aprendizaje de los años desde 1973 hasta el momento de su escritura, sino de una "actualidad pretérita" que le otorga energía, aunque Bonasso "escribe muy mal" (1997, p. 18).

Al mismo tiempo, este momento "nuevo y confuso" (Dalmaroni, 2004, p. 157) fue inundado de novedades editoriales que pusieron en primer plano las voces de un poder residual castrense con las emergencias de nuevos sujetos sociales en el entramado público. Según Miguel Dalmaroni (2004), la publicación de una constelación de novelas como Villa de Luis Gusmán, El fin de la bistoria de Liliana Heker y otras, más cercanas al corte de siglo y de la explosión sociocultural del 2001 como Los planetas de Sergio Chejefec, Ni muerto has perdido tu nombre de Luis Gusmán y El secreto y las voces de Carlos Gamerro, y Dos veces junio de Martín Kohan iniciaría un corte respecto del período inaugurado en 1984/1985 con el Nunca más y el Juicio a las Juntas. Esta bisagra en las maneras de contar la dictadura estaría dada por la instalación de un nuevo orden narrativo que "remite" al tipo realista o "literal", alejado de las estéticas construidas desde la "oblicuidad, de la fragmentación o del ciframiento alegórico" (2004, p. 159), que caracterizaban las narraciones de Héctor Tizón, Juan José Saer o Ricardo Piglia. ${ }^{11}$

Si bien este acontecimiento editorial marcó una nueva fase respecto del quietismo que había impuesto los indultos y las amnistías, se cree que no lo hacen respecto de un tipo de narraciones altamente figurativas. No lo hacen porque esos modelos, el de Nadie, nada, nunca de Saer y Respiración artificial de Piglia, no solo son novelas sobre la dictadura sino también de la dictadura, es decir, anteriores a 1985. Si estas narraciones instalan un ritmo o un modelo es porque, como vimos, se intentó establecer desde el sector predominante de la izquierda, un modelo de narrar el horror dictatorial. Hubo fuera del canon de los sectores dominantes de la izquierda intelectual otras escrituras, como las de Bonasso, por ejemplo, sí instaladas dentro de un orden literal o real, y cuyos "modos" podrían tener algún tipo de relación con este orden emergente.

Ahora bien, si existen cambios en las escrituras asociadas con la "alta" literatura se cree que se trata de una causa que se relaciona con las "oscilaciones de la cotización” (Bourdieu, 1995). En primer lugar, porque, como dice Franco Moretti (2015), el estilo es promovido por el mercado, el éxito en ventas de La voluntad. Historia de la militancia en Argentina de Anguita y Caparrós podría haber incidido en estas transformaciones narrativas. Por otra parte, y en segundo lugar, como bien sostiene Dalmaroni:

la novela argentina imagina ahora con una intensidad y una focalización antes no ensayada, las hablas privadas de los torturadores, asesinos y apropiadores en la rutina horrenda de los chupaderos (...) y las de los argentinos ordinarios que colaboraron, consintieron, o callaron y prefirieron olvidar. (2004, p. 160)

11. Se remite a los textos de Beatriz Sarlo de principios de los 80, sobre todo "Ficción y política" (1983) y "Una alucinación en dispersa agonía" (1984), en los que se jerarquizan estas lecturas desde las caracterizaciones que realiza Dalmaroni. 
La alta exposición de militares en la televisión, las confesiones de Scilingo, las notas en los diarios, dan cuenta de la habilitación de las voces privadas de otros actores sociales en el marco social de la memoria.

Estas novelas, cercanas al régimen realista, son acogidas paulatinamente por la izquierda intelectual. Se cree que si estos cambios suceden es porque los mismos escritores que forman parte del canon de lecturas en relación con la dictadura, también coquetean con el mercado y con las formas dominantes de circulación. Un diálogo entre Beatriz Sarlo, Martín Prieto, Matilde Sánchez (luego editora del suplemento $\tilde{N}$. Revista de cultura) y María Teresa Gramuglio, titulado "Literatura, mercado y crítica. Un debate", aparecido en el n 66 de Punto de vista de 2000 se centra justamente en cómo los escritores vinculados a ciertas formas, establecieron o fueron parte de alguna operación de mercado, en un contexto en el que ese campo editorial, mercantil, tenía gran influencia en el intelectual. A propósito, sobre la producción en torno al pasado reciente sostiene Gramuglio:

Las islas de Carlos Gamerro, Calle de las escuelas n¹3, o Los planetas. Novelas que trabajan sobre la historia reciente, pero en registros extraños, no previsibles. Antes que surgiera este diálogo, Beatriz sugirió la idea de la 'desaparición de la historia reciente'. Creo que es una idea equivocada si se piensa en novelas como esas, y seguro que no son las únicas. (Gramuglio, Prieto, Sánchez y Sarlo, 2000, p. 7)

\section{Consideraciones finales}

Se ha realizado un recorrido por los posicionamientos de los intelectuales teniendo en cuenta su capital simbólico y la participación en revistas que han tenido incidencia en el campo intelectual, durante la posdictadura. Estas "polémicas" en relación con el pasado reciente que, en este caso constituyen muestras de un relevamiento mayor, pueden ser leídas, en sus matices, a partir de los diversos hechos que tuvieron estrecha vinculación con el genocidio y la dictadura. Hechos que no solo inciden en la manera en la que se ve el pasado, sino que se relacionan de una u otra manera en la paulatina erosión del campo intelectual durante los años 90. Así, el Nunca más, las amnistías, el lento desembarco del mercado, la publicación y promoción de narraciones, se anudan para trazar el telón de fondo del itinerario de los posicionamientos críticos en las publicaciones periódicas.

Estas lecturas acerca del pasado reciente, fuertemente marcadas por los debates de los 60 que fueron obturados por la violencia política, como el internacionalismo y la vanguardia artística, adquirieron otros tonos que nos permiten pensar en un recorrido que va desde cierto clasismo artístico, hacia una paulatina cesión ante la hegemonía del mercado.

Por último, se cree que los cortes temporales que se han realizado permiten pensar en narraciones autónomas correspondientes a cada uno, que se retomarán en algún momento en los años posteriores al periodo posdictatorial. El cambio de los papeles del Estado respecto del pasado y la jerarquización del tema de la violencia política, así como el cuestionamiento de la teoría de los "dos 
demonios" en los 2000, invitaron a retomar las polémicas de la transición y sus años posteriores, que se hicieron eco en revistas culturales y literarias.

\section{Referencias bibliográficas}

Badiou, A. (2005). El siglo. Buenos Aires, Manantial.

Barthes, R. (1973). El grado cero de la escritura. Buenos Aires, Siglo XXI.

Barthes, R. (1993). El placer del texto seguido de Lección inaugural. Buenos Aires, Siglo XXI. (Original de 1973.)

Beceyro, R. (1997). Otra vez los fantasmas del pasado. Punto de vista. Revista de cultura. 58, 20-23.

Bourdieu, P. (1980). La mort saisit le vif. Actes de la recherche en sciencies sociales, 32-33, 3-14.

Bourdieu, P. (1995). Las reglas del arte. Génesis y estructura del campo literario. Barcelona, Anagrama. (Original de 1992.)

Casullo, N. (2004). Sobre la marcha. Cultura y politica en la Argentina (1984-2004). Buenos Aires, Colihue.

Crenzel, E. (2014). La historia política del Nunca más. La memoria de las desapariciones en Argentina. Buenos Aires, Siglo XXI. (Original de 2008.)

Dalmaroni, M. (2004). La palabra justa. Crítica y memoria en la Argentina 1960-2002. Santiago de Chile, Melusina-Ril editores.

De Diego, J. L. (2003). ¿Quién de nosotros escribirá el Facundo? Intelectuales y escritores en la Argentina. La plata, Al margen.

Feierstein, D. (2007). El genocidio como práctica social. Entre el nazismo y la experiencia argentina. Buenos Aires, Fondo de Cultura Económica.

Feierstein, D. (2018). Los dos demonios (recargado). Buenos Aires, Marea editorial.

Ferrer, C. (1989). Rodolfo Walsh: una herencia imposible. Babel. Revista de libros, 9, 27.

Franco, M. y Levin, F. (2007). Historia reciente: historia y desafíos de un campo en construcción. Buenos Aires, Paidós.

Gerbaudo, A. (2016). Politicas de exhumación. Las clases de los críticos en la universidad argentina de la posdictadura 1984-1986. Santa Fe-Los polvorines, Editorial UNL.

Giunta, A. (2008). Vanguardia, internacionalismo y politica. Arte argentino en los años sesenta. Buenos Aires, Siglo XXI.

Gramuglio, M. T.; Prieto, M.; Sánchez, M. y Sarlo, B. (2000). Literatura, mercado y crítica. Un debate. Punto de vista. Revista de cultura, 66, 1-9. 
Lvovich, D. y Bisquert, J. (2008). La cambiante memoria de la dictadura. Discursos sociales y legitimidad democrática. Buenos Aires, Universidad General Sarmiento, Biblioteca Nacional.

Moretti, F. (2015). Lectura distante. Buenos Aires, Fondo de Cultura Económica. (Original de 2005)

Nofal, R. (2001). El testimonio de la militancia montonera argentina: Miguel Bonasso. Entrepasados. Revista de historia, X (20-21), 55-72.

Nofal, R. (2010). Desaparecidos, militantes y soldados: de la literatura testimonial a los partes de guerra. En Crenzel E. (comp. y ed.), Los desaparecidos en la Argentina. Memorias, representaciones e ideas (1983-2008) (pp. 161-188). Buenos Aires, Biblos.

Panesi, J. (2018). Polémicas ocultas. La seducción de los relatos. Crítica literaria y política en la Argentina (pp. 34-46). Buenos Aires, Eterna cadencia. (Original de 2003.)

Patiño, R. (2003). Narrativas políticas e identidades intelectuales en Argentina (1990-2000). Maryland, Latinamerican Studies Center, University of Maryland.

Patiño, R. (2006). Revistas literarias y culturales argentina en los '80. Ínsula, 715-716 (julio- agosto), s/p. https://bit.ly/3wxykaE.

Pescader, C. (2017). Verdad, justicia y 'reconciliación'. Exploraciones sobre la Argentina de la posdictadura. Anuario de la Escuela de historia, 20, 163-184.

Rivera, J. (1995). El periodismo cultural. Buenos Aires, Paidós. Colihue.

Saítta, S. (2009). Del compromiso político a la crítica social en treinta años de literatura argentina. Ayer, 73, 133-157.

Sarlo, B. (1983). Ficción y política. Punto de vista. Revista de cultura, 19, 8-11.

Sarlo, B. (1984). Una alucinación en dispersa agonía. Punto de vista. Revista de cultura. 21, 1-4.

Sarlo, B. (1987). Los militares y la historia: contra los perros del olvido. Punto de vista. Revista de cultura, 30, 5-8.

Sarlo, B. (1989). Montoneros: delfines y soldados. Babel. Revista de libros, 9, 26-27.

Sarlo, B. (1992). Intelectuales y revistas. Razones de una práctica. America Cabiers du Criccal, 9-10, 9-16.

Sarlo, B. (1997). Cuando la política era joven. Punto de vista. Revista de cultura, 58, 15-19.

Schmucler, H. (1989). La única verdad es el relato. Babel. Revista de libros, 9, 8.

Schwarzböck, S. (2015). Los espantos. Estética y postdictadura. Buenos Aires, Cuarenta Ríos.

Sorendéguer, M. (2001). Los relatos sobre el pasado reciente en Argentina: una política de la memoria. Iberoamericana, 1, 1-17.

Vezzetti, H. (1996). Variaciones sobre la memoria social. Punto de vista. Revista de cultura, 56, 1-5.

Vezzetti, H. (2002). Pasado y presente. Guerra, dictadura y sociedad en la Argentina. Buenos Aires, Siglo XXI. 
Vulcano, L. (2000). Crítica, resistencia y memoria en Punto de vista. Revista de cultura. Orbis tertius, $4(7), 1-7$.

Wortman, A. (2002). Vaivienes del campo intelectual político cultural en Argentina. En Mato, D. (coord.), Estudios y Otras Prácticas Intelectuales Latinoamericanas en Cultura y Poder (s/p). Caracas, Consejo Latinoamericano de Ciencias Sociales (CLACSO).

* Bruno Ragazzi es Profesor y Licenciado en Letras por la Universidad Nacional del Nordeste. Es Auxiliar de primera categoría de las cátedras Literatura Argentina I y Seminario de Literatura Argentina II de la misma Universidad. Es doctorando en Letras con el proyecto "Narrativas sobre el pasado reciente. Circulación y recepción en el campo cultural (2003-2015)”. Ha publicado artículos en revistas nacionales.

RECIBIDO: 07/04/2021

ACEPTADO: 05/10/2021 